\title{
Detailed crustal deformation and fault rupture of the 2015 Gorkha earthquake, Nepal, revealed from ScanSAR-based interferograms of ALOS-2
}

\author{
Tomokazu Kobayashi", Yu Morishita and Hiroshi Yarai
}

\begin{abstract}
We have successfully detected widely distributed ground displacements for the 2015 Gorkha earthquake by applying a ScanSAR-based interferometry analysis of Advanced Land Observing Satellite 2 (ALOS-2) L-band data. A major displacement area extends with a length of about $160 \mathrm{~km}$ in the east-west direction, and the most concentrated crustal deformation with ground displacement exceeding $1 \mathrm{~m}$ is located $20-30 \mathrm{~km}$ east from Kathmandu. A quasi-vertical displacement estimated by combining the ascending and the descending data indicates upheaval of about $1.4 \mathrm{~m}$ at maximum. We inverted the synthetic aperture radar interferometry (InSAR) data including both of the main shock (moment magnitude (Mw) 7.8) and the largest aftershock (Mw 7.3) to construct a slip distribution model. Our model shows a nearly pure reverse fault motion with a slip amount of approximately $6 \mathrm{~m}$ at maximum, and the spatial extent is zonally distributed within a distance of 50 to $100 \mathrm{~km}$ from the surface along downdip direction. The downdip end of the slip is quite consistent with that of the interseismic coupling area geodetically inferred in previous studies. On the other hand, there is no significant slip at shallow depth in spite of the fact that the plate interface is thought to be fully locked there, may be suggesting that there still remains a potential of fault slip. The slip distribution unnaturally bifurcates in the east, and we can identify a clear-cut slip deficit area with a radius of $\sim 10 \mathrm{~km}$ just west side of the Mw 7.3 event, where the slip amount reaches only $20 \mathrm{~cm}$ at most. This area is presumably subjected to a strong shear stress which should promote a reverse fault slip. There is a possibility to produce a fault slip equivalent to Mw 7.0 in the future although we do not know if the slip heterogeneity would be smoothed out by a seismic event or an aseismic event.
\end{abstract}

Keywords: ALOS-2, InSAR, ScanSAR, Crustal deformation, Gorkha earthquake, Nepal, Slip distribution, Slip deficit

\section{Introduction}

A devastating earthquake with a moment magnitude (Mw) of 7.8 (US Geological Survey 2015) struck central Nepal on April 25, 2015, with its hypocenter located in the Gorkha region, hence called Gorkha earthquake. The death toll has surpassed 8000, and many historical structures have collapsed in Kathmandu. The earthquake is thought to have occurred at the plate interface along the Himalayan arc between the Indian plate and the Eurasian plate. A thrust fault with a NNE-SSW compressive axis was inferred from some seismic wave analyses

\footnotetext{
* Correspondence: kobayashi-t96dv@mlit.go.jp

Geospatial Information Authority of Japan, 1 Kitasato, Tsukuba, Ibaraki 305-0811, Japan
}

(Fig. 1); thus, vertical and NS-oriented ground movements associated with the reverse motion must have been involved in the ground surface changes. This earthquake is the largest event in Nepal since the 1934 Bihar-Nepal earthquake ( $\mathrm{Mw}$ 8.1) (Ambraseys and Douglas 2004; Avouac 2007). The aftershock distribution, including five seismic events of $>M 6$, extended east of a hypocenter of the main shock (Fig. 1), and a Mw 7.3 aftershock occurred approximately $150 \mathrm{~km}$ east of the hypocenter of the main shock on 12 May 2015. This event also has a thrust fault mechanism and is the largest aftershock as of this writing.

Most of the crustal deformation in the Himalaya proceeds on the Main Himalayan Trust fault (MHT) (Avouac 2003), where the Indian plate underthrusts

\section{Springer}




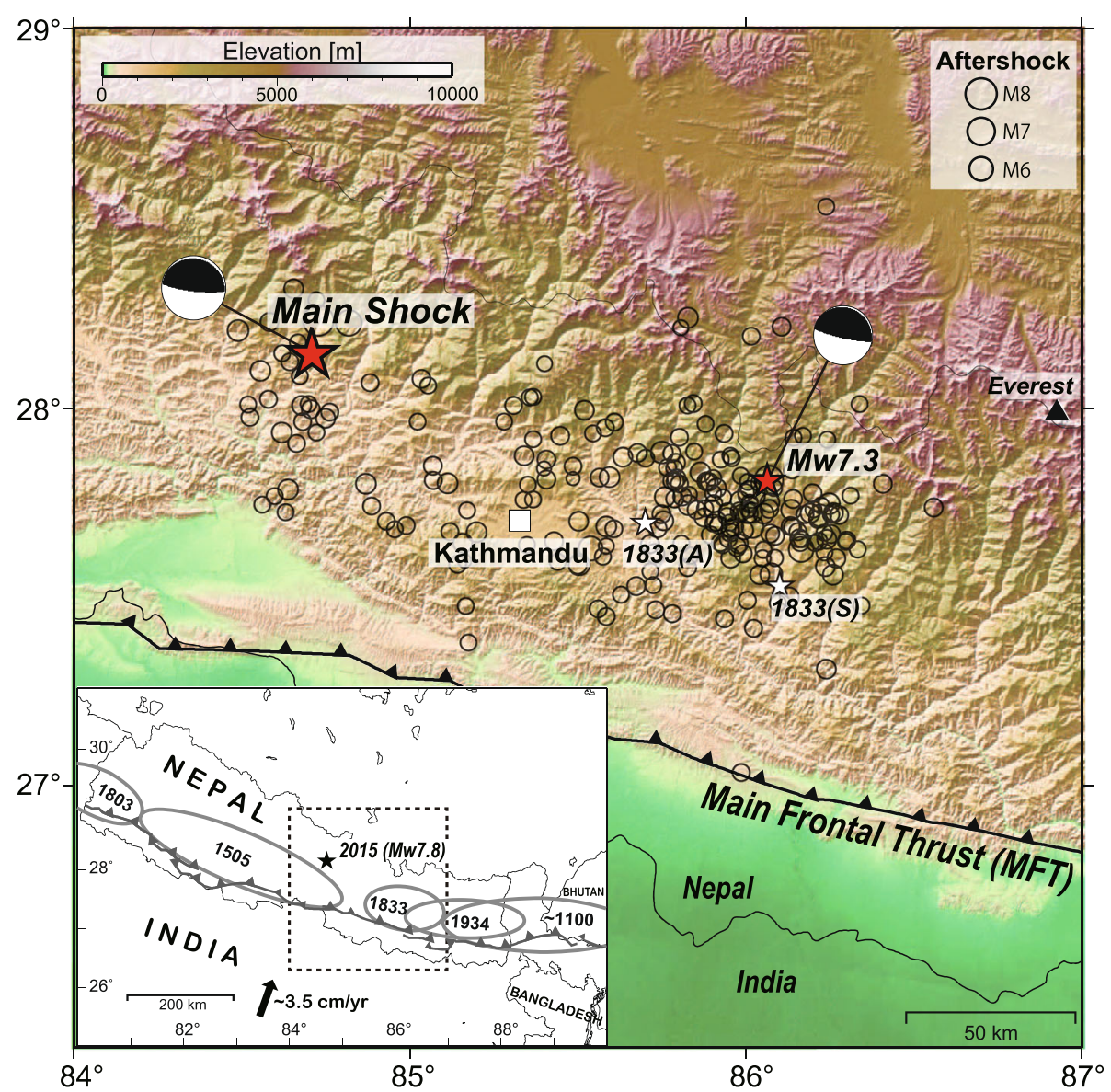

Fig. 1 Tectonic setting of Nepal. Large and small red stars mean epicenters of the main shock and the Mw 7.3 aftershock determined by the US Geological Survey (2015), respectively. Open circles represent aftershocks from April 25, 2015, to May 17, 2015. White stars mean the epicenter of the $1833 \mathrm{Mw} 7.6$ event, in which A and S stand for the locations determined by Ambraseys and Douglas (2004) and Szeliga et al. (2010), respectively. Locations of historical large earthquakes along the Himalayan arc (Avouac 2007) are shown in an inset

beneath the Eurasia plate nearly northward with $\sim 3.5 \mathrm{~cm} /$ year (Bettinelli et al. 2006). The crustal shortening rate across the Himalaya derived from geodetic measurement is $1.9 \mathrm{~cm} /$ year (Bettinelli et al. 2006). The shortening chiefly results from deformation on the MHT which absorbs about half of the total convergence rate by faulting and folding (Avouac 2007). The MHT reaches the ground surface at the front of the Himalayan belt, corresponding to the Main Frontal Thrust fault (MFT), where the secular slip rate over the Holocene is estimated to be about $2.1 \mathrm{~cm} /$ year in central Nepal (Lavé and Avouac 2000). The shortening rate from geodetic surveys is very close to the averaged slip rate, indicating that geodetic interseismic deformation is essentially elastic and released by slip on the thrust fault (Ader et al. 2012). This high convergence rate culminates in the potential of fault slip available to drive large earthquakes on the plate interface, and indeed, large earthquakes of magnitude 8 class have occurred historically.
It is known that there lies an 800-km-long seismic gap along the Himalayan arc (Avouac 2007), where little large-to-great sized rupture has occurred during the last 200-500 years (Fig. 1). There has been no remarkable earthquakes also in the source region of the 2015 event for a long term; thus, in this context, we may say that a large earthquake is an anticipated event to come. How the fault rupture of the 2015 event was involved with previous seismic events is important from the viewpoint of the seismic cycle in the Himalayan belt.

A new L-band synthetic aperture radar (SAR) satellite, called Advanced Land Observing Satellite 2 (ALOS-2), was launched in May 2014. This satellite has two main strong points for the observation of this seismic event. One is the wavelength of microwaves emitted. In general, a SAR interferometry (InSAR) using L-band is advantageous for detecting ground displacements even in non-urban areas due to its high coherence, compared with C- or X-band microwaves (Kobayashi et al. 2011; 
Amarjargal et al. 2013). The capability enables us to capture the whole picture of the crustal deformation even in mountainous areas. The other is a wide-area observation technology. This satellite possesses various observation modes, and one of them is a ScanSAR mode which has an ability to observe over broad area with a swath width of $350 \mathrm{~km}$ in one action. ALOS-2 has been designed so that we can process ScanSAR-ScanSAR interferometry. Use of ScanSAR data is even more effective for a large earthquake to quickly obtain the vast crustal deformation. Hence, a ScanSAR-based L-band InSAR is indeed suitable for mapping the spatially comprehensive and detailed crustal deformation of the 2015 Gorkha earthquake, which will contribute to answer the fundamental question of where and how the fault rupture has extended.

Several research groups have employed the ALOS-2 ScanSAR data to measure the ground displacement (Feng et al. 2015; Galetzka et al. 2015; Grandin et al. 2015; Lindsey et al. 2015; Wang and Fialko 2015) and obtained a coseismic crustal deformation map and a slip distribution on the plate boundary. They, however, basically use the ScanSAR data of the descending orbit. Even if using the ascending orbit data, the interferogram is limited to the stripmap-stripmap pair which covers only the central area of the source region. In contrast, our study has a unique point that we succeeded in mapping the deformation from the ScanSAR data for "both" the orbits. This additional information enables to directly measure the vertical movement and to discuss postseismic deformation, which is little documented in their works. The primary purpose of this paper is to rapidly report the whole picture of the 2015 Gorkha earthquake with showing crustal deformation and the fault slip distribution inferred from the ScanSAR-based InSAR data.

\section{InSAR analysis and crustal deformation}

Our InSAR images have successfully delineated the spatial patterns of coseismic deformation. Figure 2a, b shows the interferograms from the descending and the ascending orbits, respectively. The both include the occurrence dates of the main shock and the Mw 7.3 event. The used images are listed in Table 1. For the descending orbit data, we processed the ScanSAR-ScanSAR interferometry. The ScanSAR data we processed is produced by a full-aperture method in which range/azimuth compression is performed for the data whose gaps between neighboring bursts are filled with zero. On the other hand, for the ascending orbit, we made stripmapScanSAR interferograms. This is because there are no available ScanSAR images for interferometry processings due to the bad burst overlap ratios. This specific processing using the stripmap data enables us to get the crustal deformation map observed from the ascending orbit and to calculate a quasi-vertical component, discussed later. Note that only the image covering Kathmandu is a stripmap-stripmap interferogram (pair No. 3 in Table 1) acquired before the Mw 7.3 event. To remove the topographic fringes, we used the Advanced Spaceborne Thermal Emission and Reflection Radiometer (ASTER) Digital Elevation Model (DEM) data. The ALOS-2 data were processed using GSISAR software (Fujiwara and Tobita 1999; Fujiwara et al. 1999; Tobita et al. 1999; Tobita 2003). To clearly identify the fringe patterns especially for the mountainous area and to conduct a phase unwrapping more easily, we implemented filtering operations with a coefficient of 1.0 (Baran et al. 2003) and multilooking processings with $16 / 64$ looks in range/azimuth equivalent to a pixel spacing of about $180 \mathrm{~m}$. We confirmed that the number of fringes is not reduced by these operations.

The original interferograms are contaminated by a long-wavelength phase change noise of unknown causes, may be due in part to atmospheric delay. The noise are included in the entire area of the InSAR images with displacements exceeding a few tens centimeters. To pick up the crustal deformation only, we reduced the noises by the following steps. We basically followed an algorithm presented by Tobita et al. (2005), but with a slight minor correction. The far-field displacement is assumed to be zero, and we put pseudo reference points with no displacement outside of the possible deforming area. And then, the residual phases are expressed by a splineinterpolated functions (Sandwell 1987), and we subtracted the curved functions from the original interferograms. We applied this correction method to the interferograms acquired before the earthquake which should have no ground displacement and confirmed that the possible error produced by this correction method is about $10 \mathrm{~cm}$ more or less.

A major displacement area extends with a length of about $160 \mathrm{~km}$ in the east-west direction (Fig. 2). A notable fringes showing the displacement moving to the satellite are identified around Kathmandu in both orbits, and the maximum displacements with approximately 1.2 and $1.4 \mathrm{~m}$ are observed in the descending and the ascending orbits, respectively. In the northern part, the displacements moving away from the satellite are observed in both orbits. A large red star stands for the epicenter of the main shock, and there is no significant displacement further west from the epicenter, suggesting that no significant rupture propagated westward. We will show the detailed slip distribution on the fault in the next section. We cannot identify any phase discontinuities showing appearance of earthquake surface faults along either the MFT or other faults.

We can find out the locally intensive deformation in the eastern part of the interferograms, which corresponds to 
a

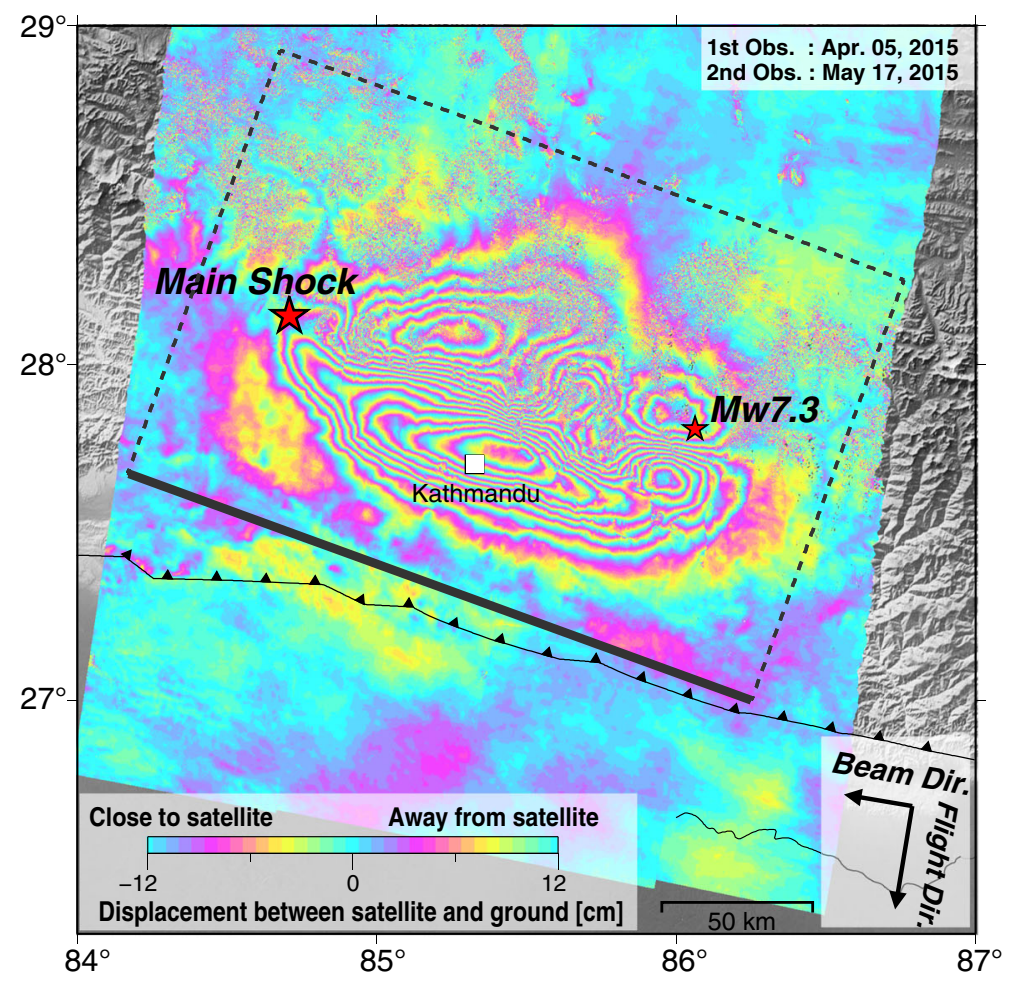

b

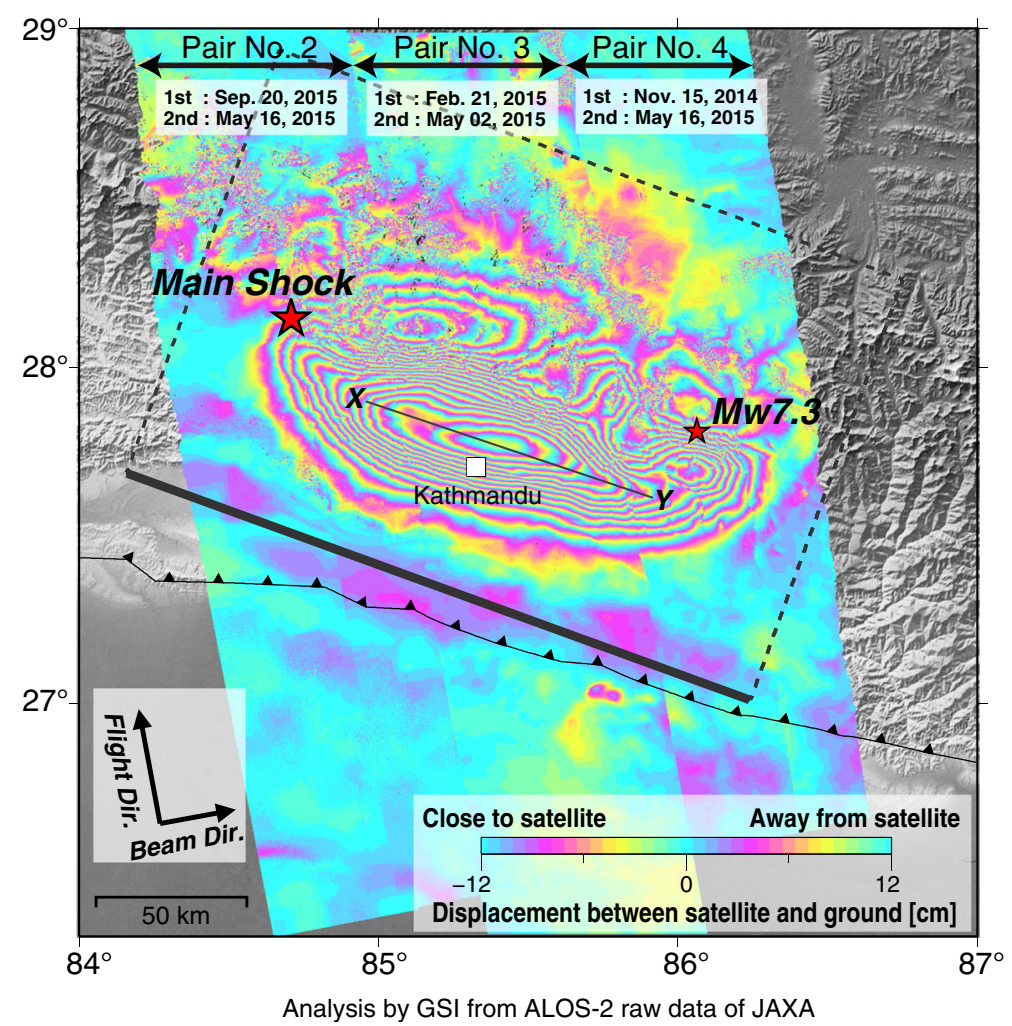

Fig. 2 a Concatenated interferograms obtained from ScanSAR-ScanSAR interferometry from a descending orbit. A frame indicates a surface projection of our fault model geometry and the thick line stands for the upper edge. $\mathbf{b}$ Same as (a) but for stripmap-ScanSAR and stripmap-stripmap interferometry from an ascending orbit 
Table 1 List of ALOS-2 images analyzed

\begin{tabular}{|c|c|c|c|c|c|c|c|c|}
\hline Pair No. & Fig. & EQ & Acquisition date & Time (UTC) & Flight dir. & Obs. mode & Incidence angle & $\mathrm{Bp}$ \\
\hline \multirow[t]{2}{*}{1} & $2 a$ & $\mathrm{M} / \mathrm{A}$ & Apr. 05, 2015 & $06: 13$ & Des & W-W & $26^{\circ}-50^{\circ}$ & $-95 m$ \\
\hline & & & May 17, 2015 & & & & & \\
\hline \multirow[t]{2}{*}{2} & $2 b$ & $\mathrm{M} / \mathrm{A}$ & Sep. 20, 2014 & 18:17 & Asc & F-W & $28^{\circ}-35^{\circ}$ & $-397 m$ \\
\hline & & & May 16, 2015 & & & & & \\
\hline \multirow[t]{2}{*}{3} & $2 b$ & M & Feb. 21, 2015 & 18:17 & Asc & $\mathrm{F}-\mathrm{F}$ & $33^{\circ}-39^{\circ}$ & $-118 m$ \\
\hline & & & May 2, 2015 & & & & & \\
\hline \multirow[t]{2}{*}{4} & $2 b$ & $\mathrm{M} / \mathrm{A}$ & Nov. 15, 2014 & 18:17 & Asc & F-W & $38^{\circ}-44^{\circ}$ & $-81 \mathrm{~m}$ \\
\hline & & & May 16, 2015 & & & & & \\
\hline \multirow[t]{2}{*}{5} & $3 a$ & M & Apr. 5, 2015 & $06: 13$ & Des & W-W & $26^{\circ}-50^{\circ}$ & $+7 \mathrm{~m}$ \\
\hline & & & May 3, 2015 & & & & & \\
\hline \multirow[t]{2}{*}{6} & $3 b$ & A & May 3, 2015 & $06: 13$ & Des & W-W & $26^{\circ}-50^{\circ}$ & $-102 m$ \\
\hline & & & May 17, 2015 & & & & & \\
\hline
\end{tabular}

Letters $\mathrm{M}$ and $\mathrm{A}$ in the column EQ represent InSAR images that include the occurrence date of the main shock (April 25, 2015) and the Mw7.3 event (May 12, 2015), respectively. Des and Asc stand for descending and ascending orbits, respectively. Letters W and F mean ScanSAR (Normal) and Stripmap (Fine [10 m]) modes, respectively. Bp means a perpendicular baseline. The path/frame numbers for ScanSAR and stripmap modes are 48/3050 and 157/530-570, respectively

the largest aftershock of Mw 7.3 indicated by a small red star. Figure 3a shows the interferograms created by two images of the pair No. 5 (Table 1), while the interferograms of Fig. $3 \mathrm{~b}$ are produced by two images of the pair No. 6 (Table 1). The former shows the crustal deformation mainly caused by the main shock only, while the latter shows that by the Mw 7.3 event only. Also, for the Mw 7.3 event, we can clearly identify a large ground displacement with a slant range shortening/lengthening of $\sim 70 / \sim 40 \mathrm{~cm}$ in the southern/northern part. In Fig. 3a, we can identify a large-displacement-less area where the Mw 7.3 event occurred. It suggests the rupture stopped once around $86^{\circ} \mathrm{E}$, and after that, the Mw 7.3 event occurred so as to compensate the slip deficit.

Figure 4 shows a quasi-vertical component, calculated from the ascending and the descending data of Fig. 2 (Fujiwara et al 2000). Now, the quasi up-down plane is tilted to the south by $7^{\circ}-9^{\circ}$ for the satellite configuration. There is a difference of 2 weeks on the acquired dates between the ScanSAR-based interferograms (pair Nos. 1, 2 , and 4 in Table 1) and the stripmap-stripmap ones (pair No. 3 in Table 1), so some readers may think that it prevents from the estimate due to the effect of postseismic deformation and/or the Mw 7.3 event. However, it seems that these effects can be negligible for the estimate. In the interferograms of Fig. 2b, the fringes gradually connect to adjacent images without serious phase discontinuities, suggesting that the interferogram is little affected by the postseismic deformation during the period. We will have further discussion on the postseismic deformation later. And then, seeing Fig. 3b, the area is not subjected to the crustal deformation caused by the Mw 7.3 event; thus, we can safely say that the crustal deformation is not contaminated by the Mw 7.3 event.
The red and blue in Fig. 4a represent uplift and subsidence, respectively. The uplift area is distributed in the southern region, and the maximum displacement of $\sim 1.5 \mathrm{~m}$ is estimated around $20 \mathrm{~km}$ northeast from Kathmandu. Figure $4 \mathrm{~b}$ shows the vertical displacement profiles along cross-sectional lines in the downdip component. The ground is gradually uplifted from the side of the MFT up to $\sim 1.5 \mathrm{~m}$ at maximum (profile B-B'), but the vertical movement turns to be subsidence in the mountainous side with about $70 \mathrm{~cm}$ at most (profile A-A'). As expected from the source mechanism, a vertical component is predominant, and the spatial pattern is consistent with a reverse-fault motion.

\section{Fault slip distribution}

We construct a slip distribution model by a least squares approach (e.g., Kobayashi et al. 2012). In the inversion, we use both of the ascending and the descending orbit data shown in Fig. 2. The fault geometry is assumed to be a plane fault. We set a rectangular fault with $220 \mathrm{~km}$ long and $150 \mathrm{~km}$ wide, corresponding to the plate interface between the Indian and the Eurasian plates. The fault is divided into square patches with a size of $10 \times$ $10 \mathrm{~km}$. The strike and the dip angles are set to be $290^{\circ}$ and $10^{\circ}$, respectively. The fault top position is fixed to a depth of $1 \mathrm{~km}$ below the surface. In this fault setting, the patches corresponding to hypocenters of the main shock and the Mw 7.3 event are located at about 13 and $15 \mathrm{~km}$ in depth, respectively, which are consistent with hypocenters determined by seismic data (10 and $15.5 \mathrm{~km}$ ) (US Geological Survey 2015). The fault geometry was basically fixed under an assumption that the fault plane intersects the surface along the MFT, but we tried several cases with slightly changing strike/dip to 
a

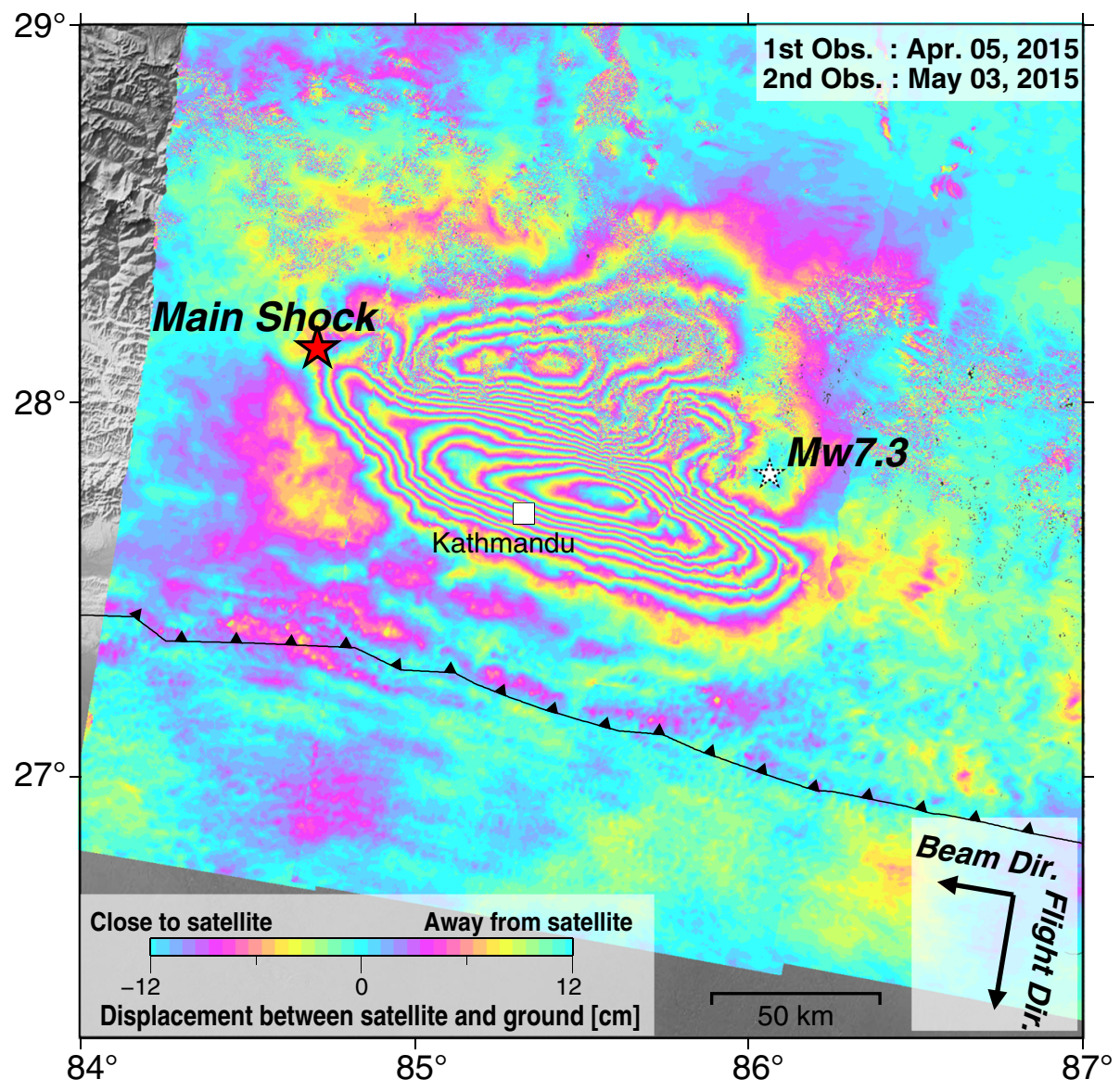

b

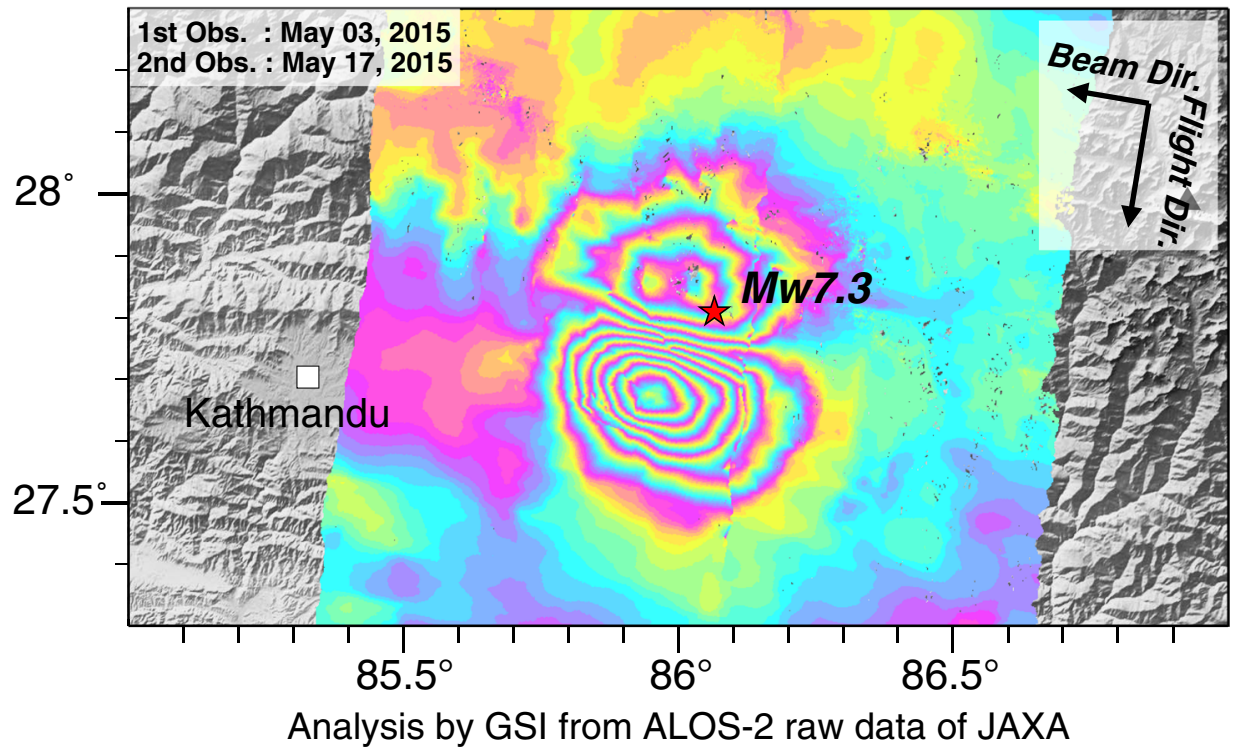

Fig. 3 a Concatenated interferograms obtained from ScanSAR-ScanSAR interferometry produced by data acquired before the Mw 7.3 event. b Interferograms showing the crustal deformation associated with the Mw 7.3 event 


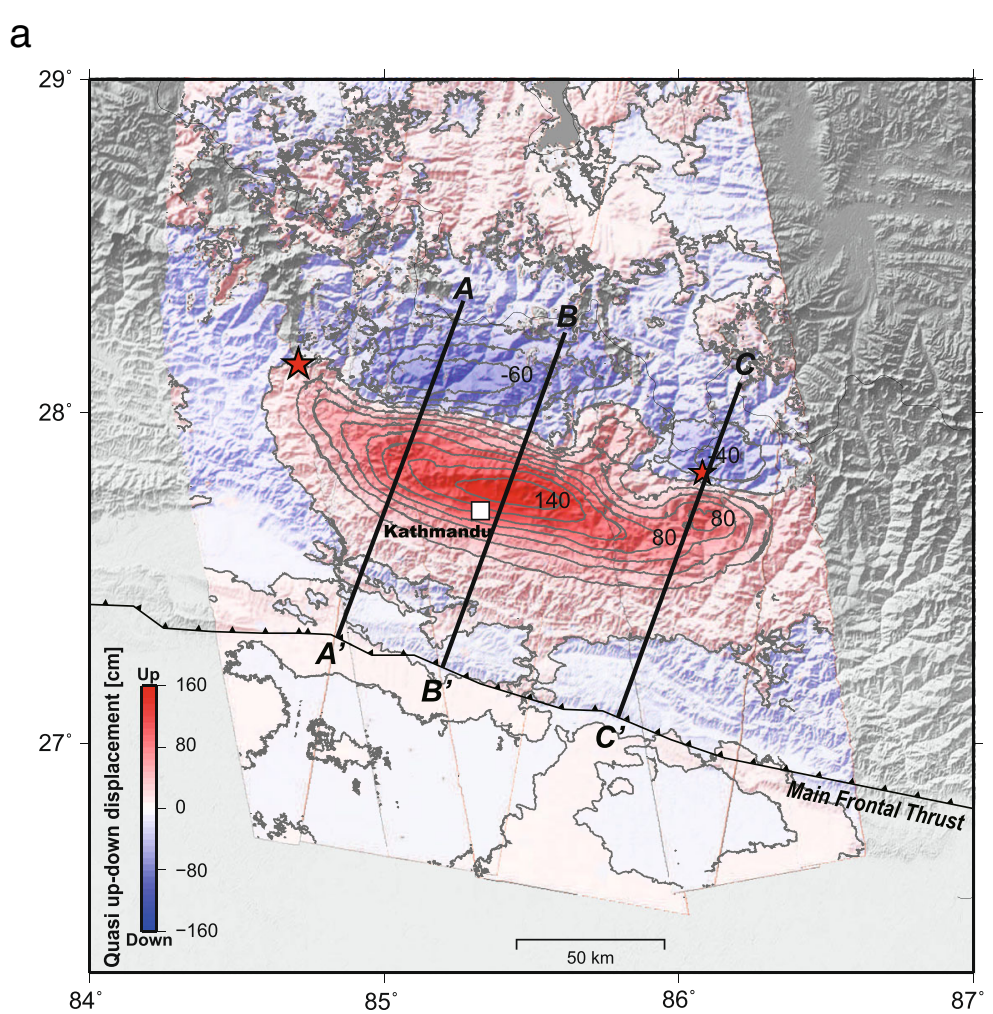

b

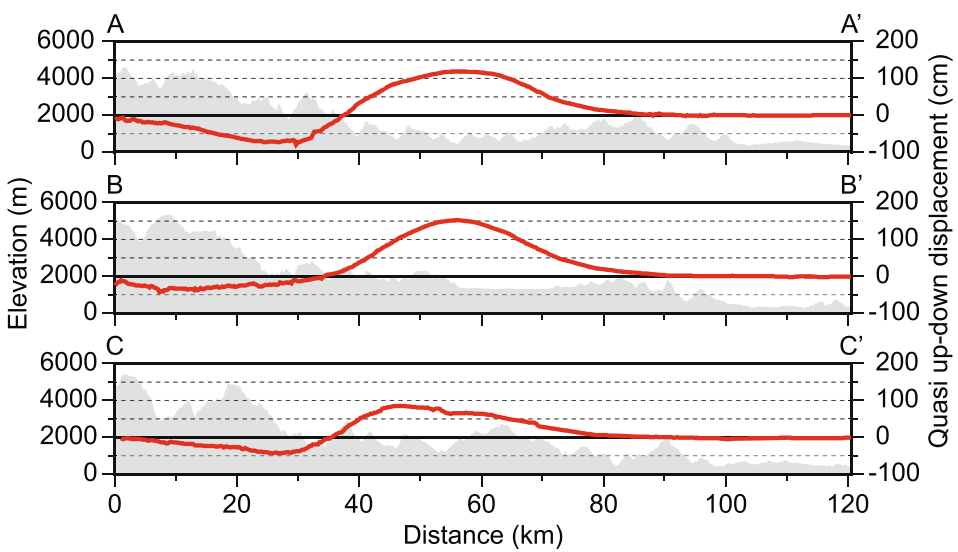

Fig. 4 a Quasi-vertical component displacement calculated using the InSAR data of Fig. 2a, b. Red and blue represent upheaval and subsidence, respectively. The contour interval is $20 \mathrm{~cm}$. b Displacement profiles along cross-sectional lines shown in Fig. 4a. Shaded profiles indicate the corresponding topography

confirm the sensitivity and/or stability to the model solution. As far as we investigated, similar slip distributions were derived in any cases without being greatly influenced by the fault geometry, but unnatural normal slips sometimes appear at some patches around the hypocentral area. To suppress the instability which might be attributed to the uncertainty of the fault geometry, we here gave constraints that allow a reverse dip-slip component only, a rake angle ranging from $0^{\circ}$ to $180^{\circ}$. We use the dislocation equations proposed by Okada
(1985) to calculate the surface displacement in the variable line of sight (LOS) directions. Only the dip-slip and strike-slip components are estimated for each patch. A large number of model parameters give rise to instability of the solution. To stabilize the solution, we here impose a spatial smoothness constraint on the slip distribution using a Laplacian operator. The relative weight of the constraints is determined by the Akaike's Baysian information criterion (Akaike 1980). Here, we assume a rigidity of $30 \mathrm{GPa}$. 
The data points of the interferograms are too many to be easily assimilated in a modeling scheme. In order to reduce the number of data for the modeling analysis, we resample the interferogram data beforehand, using a quadtree decomposition method. Essentially, we follow an algorithm presented by Jónsson et al. (2002). For a given quadrant, if after removing the mean, the residue is greater than a prescribed threshold (2 $\mathrm{cm}$ in our case), the quadrant is further divided into four new quadrants. This process is iterated either until each block meets the specified criterion or until the quadrant reaches a minimum block size $(8 \times 8$ pixels in our case).

We cannot neglect the contribution of the cross-terms of the covariance matrix for the InSAR data, inasmuch as they have a strong spatial correlation in general, which largely results from the variations of atmospheric water vapor (Lohman and Simons 2005; Fukahata and Wright 2008). We incorporate the cross-terms of the covariance matrix in the inversion scheme, following the equation presented by Fukahata and Wright (2008), and now take the characteristic correlation distance of errors to be $10 \mathrm{~km}$ (Wright et al. 2003; Fukahata and Wright 2008).

Figure 5a shows the estimated slip distribution, and Fig. 6 shows the LOS displacement field calculated from the derived model. Our model reproduces well the LOS displacement field with the residual of about one fringe for both the ascending and descending data.

The major slip occurred with a maximum slip amount of approximately $6.3 \mathrm{~m}$ beneath the area $20-30 \mathrm{~km}$ northeast from Kathmandu, which is located in $80 \mathrm{~km}$ east-southeast of the hypocenter. No significant slip is identified further west from the hypocenter. The seismic rupture is thought to have propagated eastward unilaterally, may be suggesting that the forward rupture directivity would generate a so-called killer pulse (Heaton et al. 1995). The composite effects consisting of the large slip and the rupture directivity may culminate in the

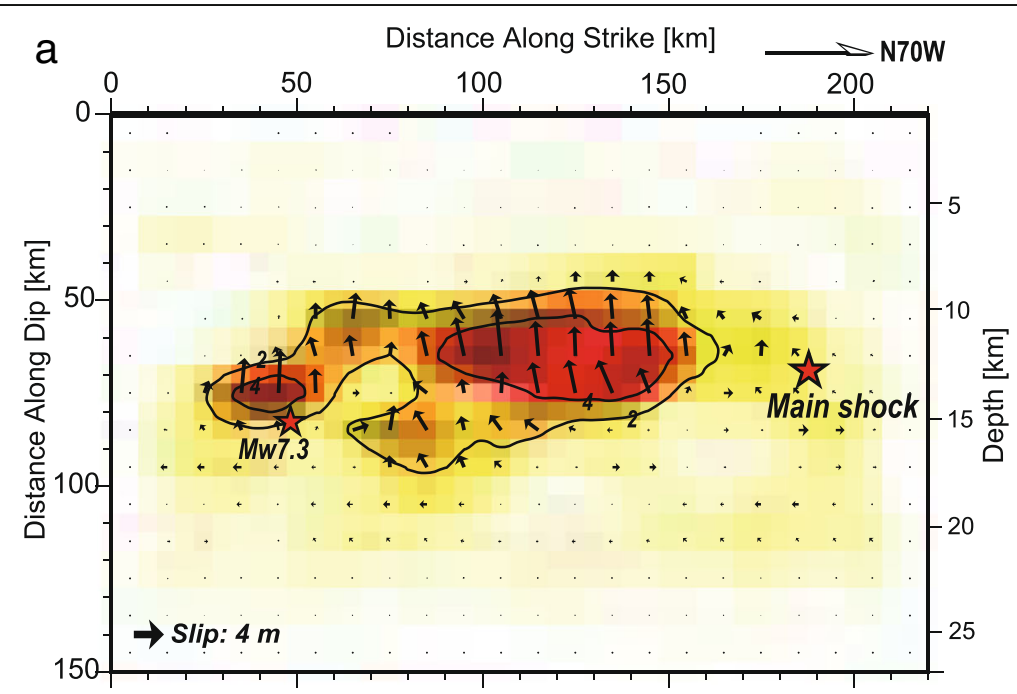

b

\section{C}
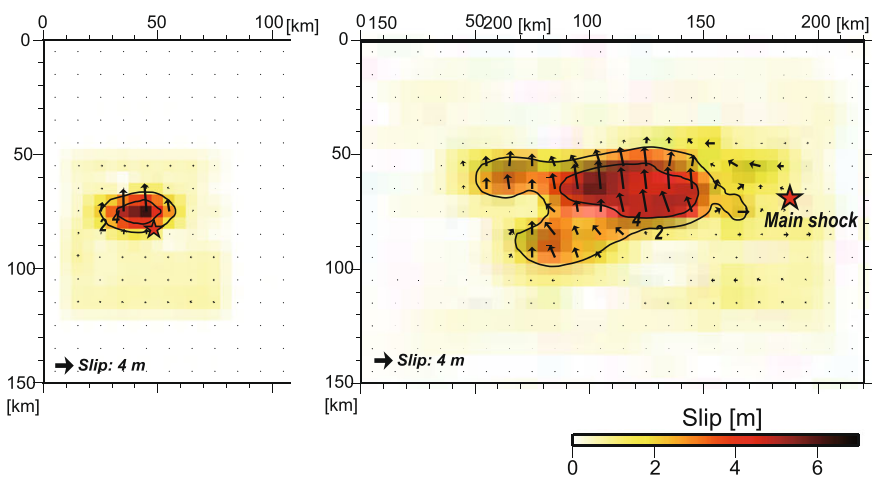

Fig. 5 a Slip distribution inferred from the inversion of the InSAR displacement. The arrows show slip vectors of the hanging wall. The contour interval is $2 \mathrm{~m}$. Large and small red stars mean epicenters projected on the fault plane for the main shock and the Mw 7.3 aftershock, respectively. b Same as (a) but for the Mw 7.3 event only. The used data are the pair No. 6 in Table 1. c Same as (a) but for the main shock only. The used data are the pair No. 5 in Table 1 
a

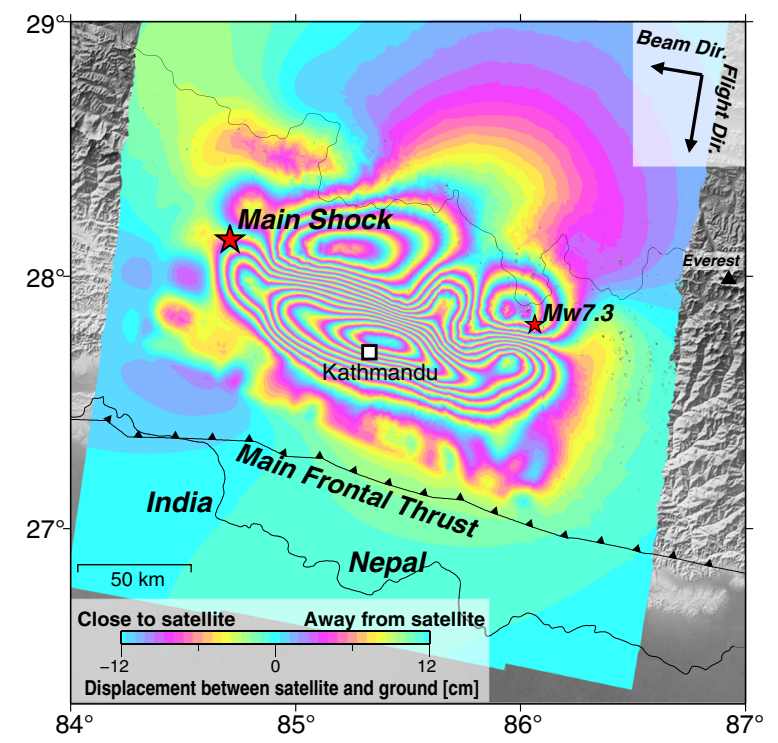

C

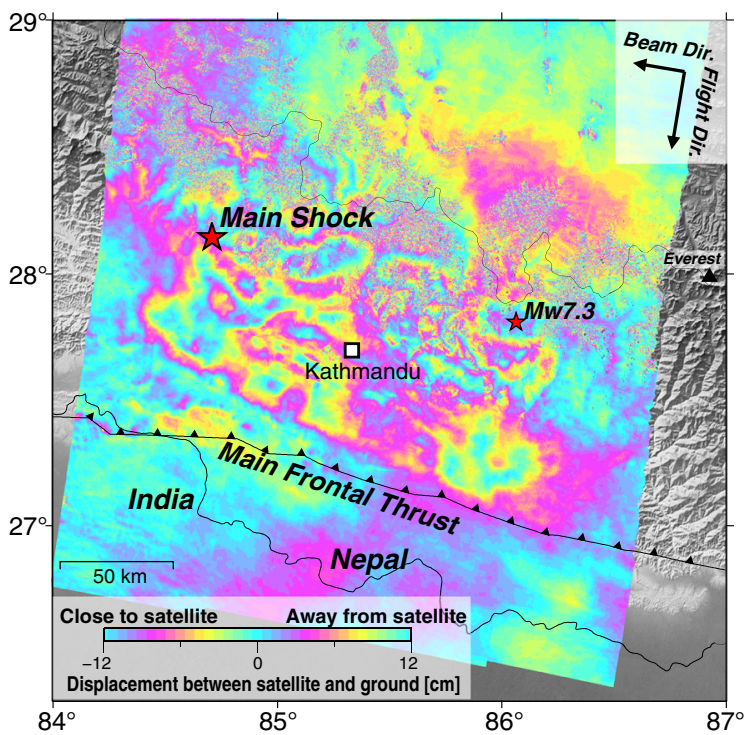

b

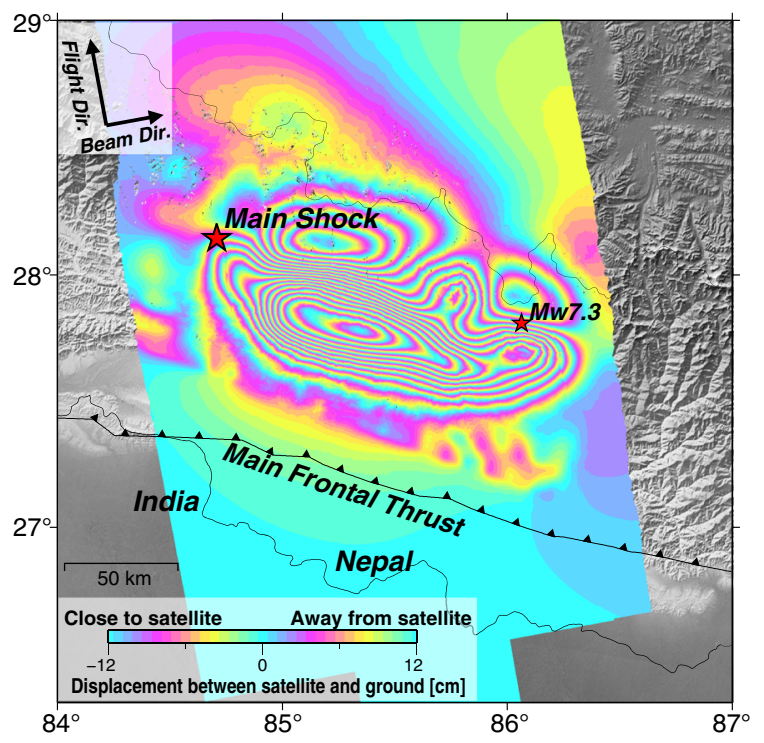

d

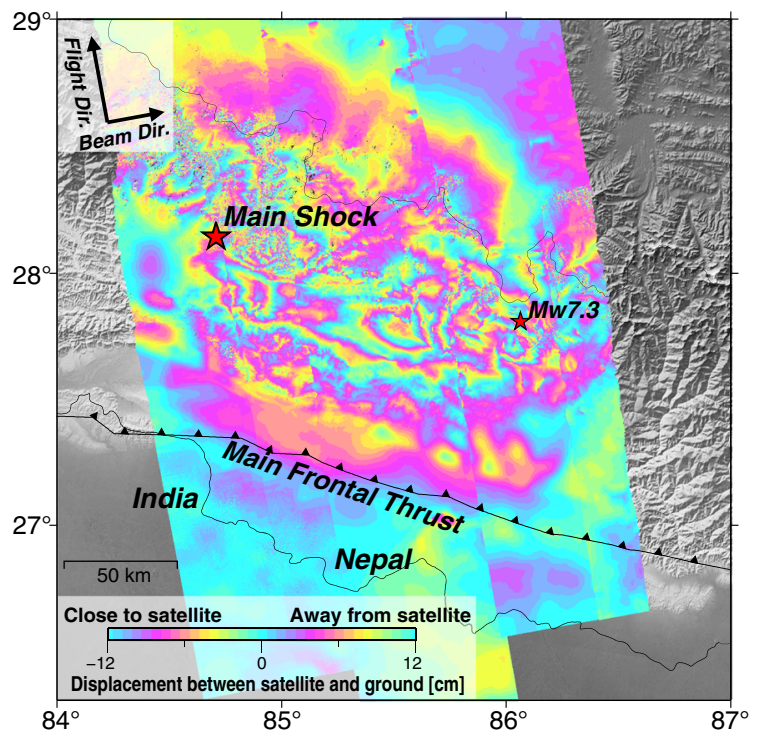

Fig. 6 a LOS displacement field predicted from the model of Fig. 5a, corresponding to Fig. 2a. b Same as (a) but for Fig. 2b. c, d Residuals between the observations (Fig. 2) and the calculations (Fig. 6a, b)

serious disasters. The slips are nearly pure reverse fault motion, but on the deeper portion have a slight rightlateral component. There is a locally distributed slip in the eastern part with a peak slip amount of about $6.2 \mathrm{~m}$, corresponding to the slip caused by the $\mathrm{Mw} 7.3$ event (Fig. 3b). The model predicts an uplift of $1.4 \mathrm{~m}$ and a southward movement of $1.1 \mathrm{~m}$ at maximum. The total estimated moment magnitude including both the main shock and the Mw 7.3 event is 7.8 (seismic moment $7.0 \times 10^{20} \mathrm{Nm}$ ). Inverting the InSAR data of pair Nos. 5 and 6 which are for the main shock only and the $\mathrm{Mw}$ 7.3 event only, respectively, the estimated moment magnitude is 7.8 (seismic moment $6.1 \times 10^{20} \mathrm{Nm}$ ) and 7.3 (seismic moment $1.1 \times 10^{20} \mathrm{Nm}$ ), respectively.

\section{Discussion}

The major slip area of our model is zonally limited within a distance of $50-100 \mathrm{~km}$ from the surface along downdip. First, focusing on the deep part, the downdip end of the slip is quite consistent with an elastically strain-accumulated depth. Geodetic studies have suggested that the MHT is fully locked from the surface to a distance of approximately $100 \mathrm{~km}$ downdip (Bilham et al. 1997; Larson et al. 1999; Ader et al. 2012) due to 
probably thermally enhanced ductile flow where aseismic creep prevails (Cattin and Avouac 2000). It is supposed that the elastic strain is not accumulated at the deep part, and the model-derived downdip extent agrees well with the idea of a spatial balance between strain accumulation and release.

On the other hand, there is no significant slip shallower than $50 \mathrm{~km}$ along downdip. Our model demonstrates that the rupture did not propagate to the subsurface. The geodetic data, however, indicates that the MHT has a high interseismic coupling also along the frontal zone (Ader et al. 2012), and some events did break the surface (Sapkota et al. 2013). Thus, it is likely that there still remains a potential to release the accumulated strain. The discussion of whether the slip in the frontal part would occur in future and of whether the slip occurs as either coseismic or aseismic style is beyond this paper. A successive geodetic monitoring will be helpful in addressing this question, and understanding of how the slip deficit is accumulated/released on the MHT.

The striking point on our model is that the slip bifurcates unnaturally in the western part near the $\mathrm{Mw} 7.3$ event. We can clearly identify that there is a clear-cut slip deficit area with a radius of $\sim 10 \mathrm{~km}$ just west side of the $\mathrm{Mw} 7.3$ event, surrounded by the bifurcated slip areas (Fig. 5a), schematically illustrated in Fig. 8. The slip amount reaches only $20 \mathrm{~cm}$ at most. To confirm some effect on fault configuration and/or dataset carefully, we tried various fault models with changing strike and dip and changed the dataset to only descending data and so on, but this slip deficit appears in any cases; hence, it seems to be a reliable result.

Considering the strong spatial contrast on slip, this area is presumably under a strong shear stress which should promote a reverse fault slip. Roughly calculating the Coulomb Failure Function change $(\triangle \mathrm{CFF})$ using the fault model of Fig. 5a as a source fault, the unslipped area is subjected to $\triangle \mathrm{CFF}$ of about $+5 \mathrm{MPa}$, assuming 0.4 as an effective coefficient of friction according to Stein et al. (1994). If assuming that this area could have a slip amount of $4 \mathrm{~m}$ as is the case for the surrounding area, there exists a seismic potential to release approximately $\mathrm{Mw}$ 7.0. Although there is no data to know if the slip heterogeneity would be smoothed out by a seismic event or an aseismic one, it is highly probable that a slip equivalent to $\mathrm{Mw} \sim 7.0$ would occur in the future. To prevent/mitigate the next disaster, it is vital to continuously monitor the slip gap because we cannot rule out a possibility of an impending seismic event.

The maximum slip of the largest aftershock is almost the same as that of the main shock although the slip area is rather local. In general, the stress drop is proportional to a ratio of a slip amount to a characteristic rupture dimension (e.g., Lay and Wallace 1995). With the seismological knowledge, the similar slip amounts presumably imply that the stress drop for the largest aftershock is higher than that for the main shock, which means that there was a strong localized asperity. The complicated slip behavior showing the slip deficit and the localized asperity may suggest that there is strong heterogeneity on frictional properties in the eastern side of the source region.

The ScanSAR-based interferograms of the ascending orbit (Fig. 2b) provide us an opportunity to discuss the postseismic deformation. This is because there is a difference of 2 weeks on observation dates between the pair No. 3 and the other two; thus, if there would be, it enables to directly estimate the postseismic deformation during the early stage. Figure 7 shows a LOS displacement profile along a cross-sectional X-Y drown in Fig. 2b. Vertical dotted lines represent the boundaries between the neighboring swaths. The displacement between the pairs of Nos. 2 and 3 gradually connects one another. Although the error $(\sim 10 \mathrm{~cm}$ at most) which can be mainly produced by the long-wavelength noise correction is possibly included in each interferogram, the

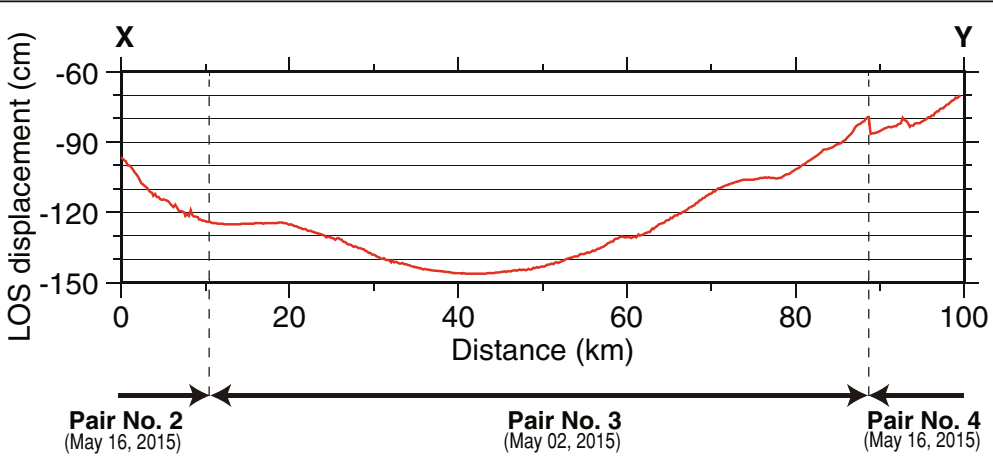

Fig. 7 Displacement profile along a cross-sectional line X-Y shown in Fig. 2b. The dates within the parentheses indicate the observation dates of slave images 


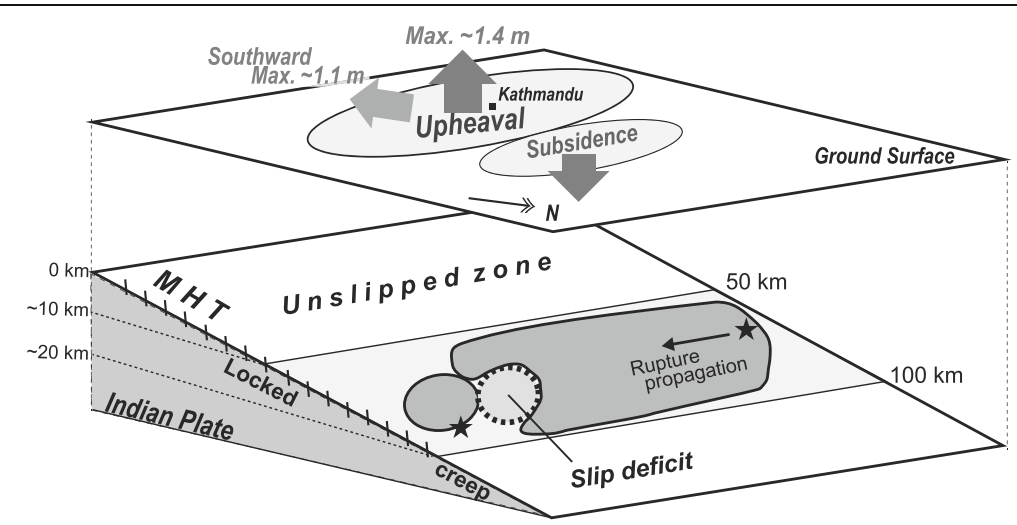

Fig. 8 Schematic view for the 2015 Gorkha earthquake interpreted from the InSAR analysis. A top layer represents the spatial pattern of ground deformation. The lower part shows a simplified diagram of the rupture/un-ruptured areas for the 2015 Gorkha earthquake on the MHT

displacement field seems to be little affected by the postseismic deformation exceeding the measurement error level. On the other hand, for the boundary between Nos. 3 and 4 , it is rather difficult to confirm the postseismic deformation because the displacement field is contaminated by the coseismic deformation of the largest aftershock which is predicted to be about $-20 \mathrm{~cm}$ by our model. Thus, we cannot have meaningful discussion any more using these interferograms.

We removed the long-wavelength phase signals in this study. The correction method we employed effectively reduces the noise and clearly shows up the coseismic deformation. At first sight, the readers may think that this approach works well for all cases of crustal deformation observation. However, this method can hardly distinguish true long-wavelength deformation signal from noise, even if there would be. There is a possibility that we fail to detect some important deformation signal. Thus, we here mention that the use of the method requires careful caution. At present, there is no alternative way but to wait for new approach to essentially reduce noise.

The $1934 \mathrm{Mw} 8.1$ and the $1833 \mathrm{Mw} 7.6$ events have historically occurred nearby the source region during the last few hundred years (Ambraseys and Douglas 2004) (Fig. 1). The rupture area presumably does not overlap that of the 1934 event substantially (Sapkota et al. 2013). On the other hand, the hypocenter of the 1833 event is estimated to be in and around the rupture zone of the 2015 event (Ambraseys and Douglas 2004; Szeliga et al. 2010) (Fig. 1); thus, there seems to be an intimate relationship between the two events This region is thought to be fully locked with the slip deficit rate of around $2 \mathrm{~cm} /$ year (Bilham et al. 1997; Ader et al. 2012). Taking the lapse time from the 1833 event into account and assuming that the slip deficit rate on the fault has been stationary over the past several centuries, a slip amount equivalent to $3.6 \mathrm{~m}$ should be accumulated until the 2015 event. Although the detailed spatial extent of the rupture for the 1833 event is little known, considering the hypocenter and the balance of the strain accumulation/release, it is possible that the 2015 event ruptured again the slip area of the 1833 event.

\section{Conclusions}

We applied ScanSAR-ScanSAR and stripmap-ScanSAR interferometry using ALOS-2 data to the 2015 Gorkha earthquake in Nepal and succeeded in mapping the widely distributed crustal deformation and the spatially detailed fault slip. The obtained knowledge is conceptually summarized in Fig. 8. The following conclusions were derived from the analyses.

(1) A major displacement area extends east of the epicenter with a length of about $160 \mathrm{~km}$. Large slant range shortenings with $\sim 1.5 \mathrm{~m}$ are observed around Kathmandu in both orbits.

(2) Combining the ascending and the descending orbit data, a maximum uplift about $1.5 \mathrm{~m}$ is estimated around $20 \mathrm{~km}$ northeast from Kathmandu.

(3) Our fault model shows nearly pure reverse-fault motions on the MHT. A major slip is inferred around Kathmandu with a slip amount of $\sim 6.3 \mathrm{~m}$ at maximum. In the eastern edge of the slip area, a locally distributed large slip associated with the Mw 7.3 event is estimated with a slip amount of $\sim 6.2 \mathrm{~m}$ at maximum.

(4) The slip is zonally distributed within a distance of 50 to $100 \mathrm{~km}$ from the surface along downdip. The downdip end of the slip is quite consistent with that of the interseismic coupling area geodetically inferred in previous studies.

(5) There is a clear slip deficit area with a radius of $\sim 10 \mathrm{~km}$ just west side of the Mw 7.3 event. This area is presumably subjected to a strong shear stress which should promote a reverse slip, and there 


\section{remains a possibility to produce a fault slip equivalent to $\mathrm{Mw} \sim 7.0$.}

\section{Competing interests}

The authors declare that they have no competing interests.

\section{Authors' contributions}

TK analyzed the InSAR, constructed the slip distribution model, and drafted the manuscript. YM made the InSAR data with reducing noises, calculated 2.5D displacement field, and revised the manuscript. HY managed this study and revised the manuscript. All authors read and approved the final manuscript.

\section{Acknowledgements}

ALOS-2 data were provided from the Earthquake Working Group under a cooperative research contract with JAXA (Japan Aerospace Exploration Agency). The ownership of ALOS-2 data belongs to JAXA. We used Generic Mapping Tools (GMT) provided by Wessel and Smith (1998) to construct the figures. We used ASTER GDEM for the InSAR analyses and the topography mapping. ASTER GDEM is a product of METI (Ministry of Economy, Trade and Industry) and NASA. We thank two anonymous reviewers and the editor for their helpful comments to improve our manuscript.

\section{Received: 13 August 2015 Accepted: 6 November 2015 Published online: 14 December 2015}

\section{References}

Ader T, Avouac JP, Liu-Zeng J, Lyon-Caen H, Bollinger L, Galetzka J, Genrich J, Thomas M, Chanard K, Sapkota SN, Rajaure S, Shrestha P, Ding L, Flouzat M (2012) Convergence rate across the Nepal Himalaya and interseismic coupling on the Main Himalayan Thrust: implications for seismic hazard. J Geophys Res 117:B044403. doi:10.1029/2011JB009071

Akaike H (1980) Likelihood and the Bayes procedure. In: Bernardo JM, DeGroot MH, Lindley DV, Smith AFM (eds) Bayesian Statistics. University Press, Valencia

Amarjargal S, Kato T, Furuya M (2013) Surface deformations from moderate-sized earthquakes in Mongolia observed by InSAR. Earth Planets Space 65:713-723. doi:10.5047/eps.2012.12.015

Ambraseys N, Douglas JJ (2004) Magnitude calibration of north Indian earthquakes. Geophys J Int 159:165-206. doi:10.1111/j.1365-246X.2004. 02323.x

Avouac JP (2003) Mountain building, erosion and the seismic cycle in the Nepal Himalaya. Adv Geophys 46:1-80. doi:10.1016/S0065-2687(03)46001-9

Avouac JP (2007) Dynamic processes in extensional and compressional settings-mountain building: from earthquakes to geological deformation. Treatise Geophy 6:377-439

Baran I, Stewart MP, Kampes BM, Perski Z, Lilly P (2003) A modification to the Goldstein radar interferogram filter. IEEE Trans Geosci Remote Sens 41:2114-2118

Bettinelli P, Avouac JP, Flouzat M, Jouanne F, Bollinger L, Willis P, Chitraker GR (2006) Plate motion of India and interseismic strain in the Nepal Himalaya from GPS and DORIS measurements. J Geod 80:567-589. doi:10.1007/s00190-006-0030-3

Bilham R, Larson K, Freymuller J (1997) GPS measurements of present-day convergence across the Nepal Himalaya. Nature 386:61-64. doi:10.1038/386061a0

Cattin R, Avouac JP (2000) Modeling mountain building and the seismic cycle in the Himalaya of Nepal. J Geophys Res 105:13389-13407

Feng G, Li Z, Shan X, Zhang L, Zhang G, Zhu J (2015) Geodetic model of the 2015 April 25 Mw 7.8 Gorkha Nepal Earthquake and Mw 7.3 aftershock estimated from InSAR and GPS data. Geophys I Int 203:896-900. doi:10.1093/gji/ggv335

Fujiwara S, Tobita M (1999) SAR interferometry techniques for precise surface change detection. J Geod Soc J.jn 45:283-295 (in Japanese with English abstract)

Fujiwara S, Tobita M, Murakami M, Nakagawa H, Rosen PA (1999) Baseline determination and correction of atmospheric delay induced by topography of SAR interferometry for precise surface change detection. J Geod Soc Jpn 45:315-325 (in Japanese with English abstract)

Fujiwara S, Nishimura T, Murakami M, Nakagawa H, Tobita M, Rosen PA (2000) 2. 5-D surface deformation of M6.1 earthquake near Mt Iwate detected by SAR interferometry. Geophys Res Lett 27:2049-2052
Fukahata Y, Wright TJ (2008) A non-linear geodetic data inversion using ABIC for slip distribution on a fault with an unknown dip angle. Geophys I Int 173:353-364. doi:10.1111/j.1365-246X.2007.03713.x

Galetzka J, Melgar D, Genrich JF, Geng J, Owen S, Lindsey EO, Xu X, Bock Y, Avouac JP, Adhikari LB, Upreti BN, Pratt-Sitaula B, Bhattarai TN, Sitaula BP, Moore A, Hudnut KW, Szeliga W, Normandeau J, Fend M, Flouzat M, Bollinger L, Shrestha P, Koirala B, Gautam U, Bhatterai M, Gupta R, Kandel T, Timsina C, Sapkota SN, Rajaure S, Maharjan N (2015) Slip pulse and resonance of Kathmandu basin during the 2015 Mw 7.8 Gorkha earthquake, Nepal imaged with space geodesy. Science 349:1091-1095. doi:10.1126/science.aac6383

Grandin R, Vallée M, Satriano C, Lacassin R, Klinger Y, Simoes M, Bollinger L (2015) Rupture process of the Mw =7.9 2015 Gorkha earthquake (Nepal): insights into Himalayan megathrust segmentation. Geophys Res Lett 42. doi:10.1002/ 2015GL066044

Heaton TH, Hall JF, Wald DJ, Halling MW (1995) Response of highrise and base-isolated buildings to hypothetical MW 7.0 blind thrust earthquake. Science 267:206-211

Jónsson S, Zebker H, Segall P, Amelung F (2002) Fault slip distribution of the 1999 Mw 7.1 Hector Mine, California, earthquake, estimated from satellite radar and GNSS measurements. Bull Seismol Soc Am 92:1377-1389

Kobayashi T, Tobita M, Nishimura T, Suzuki A, Noguchi Y, Yamanaka M (2011) Crustal deformation map for the 2011 off the Pacific coast of Tohoku Earthquake, detected by InSAR analysis combined with GEONET data. Earth Planets Space 63:621-625. doi:10.5047/eps.2011.06.043

Kobayashi T, Tobita M, Koarai M, Okatani T, Suzuki A, Noguchi Y, Yamanaka M, Miyahara B (2012) InSAR-derived crustal deformation and fault models of normal faulting earthquake (Mj7.0) in Fukushima-Hamadori area. Earth Planets Space 64:1209-1221. doi:10.5047/eps.2012.08.015

Larson KM, Bürgmann R, Bilham R, Freymueller JT (1999) Kinematics of the India-Eurasia collision zone from GPS measurements. J Geophys Res 104:1077-1093

Lavé J, Avouac JP (2000) Active folding of fluvial terraces across the Siwaliks Hills, Himalaya of central Nepal. J Geophys Res 105:5735-5770

Lay T, Wallace TC (1995) Modern global seismology. Academic Press, San Diego, pp 376-377

Lindsey EO, Natsuaki R, Xu X, Shimada M, Hashimoto M, Melgar D, Sandwell DT (2015) Line of sight displacement from ALOS-2 interferometry: Mw 7.8 Gorkha earthquake and Mw 7.3 aftershock. Geophys Res Lett 42. doi:10.1002/2015GL065385

Lohman RB, Simons M (2005) Some thoughts on the use of InSAR data to constrain models of surface deformation: noise structure and data downsampling. Geochem Geophys Geosyst 6:Q01007. doi:10.1029/ 2004GC000841

Okada Y (1985) Surface deformation due to shear and tensile faults in a halfspace. Bull Seismol Soc Am 75:1135-1154

Sandwell DT (1987) Biharmonic spline interpolation of Geos-3 and Seasat altimeter data. Geophys Res Lett 14:139-142

Sapkota SN, Bollinger L, Klinger Y, Tapponnier P, Gaudemer Y, Tiwari D (2013) Primary surface ruptures of the great Himalayan earthquakes in 1934 and 1255. Nat Geosci 6(1):71-76

Stein RS, King GCP, Lin J (1994) Stress triggering of the 1994 M =6.7 Northridge, California, earthquake by its predecessors. Science 265:1432-1435

Szeliga W, Hough S, Martin S, Bilham R (2010) Intensity, magnitude, location and attenuation in India for felt earthquakes since 1762. Bull Seismol Soc Am 100(2):570-584

Tobita M (2003) Development of SAR interferometry analysis and its application to crustal deformation study. J Geod Soc Jpn 49:1-23 (in Japanese with English abstract)

Tobita M, Fujiwara S, Murakami M, Nakagawa H, Rosen PA (1999) Accurate offset estimation between two SLC images for SAR interferometry. J Geod Soc Jpr 45:297-314 (in Japanese with English abstract)

Tobita M, Munekane H, Matsuzaka S, Kato M, Yarai H, Murakami M, Fujiwara S, Nakagawa H, Ozawa T (2005) Studies on InSAR data processing technique. Bull GSI 106:37-49 (in Japanese)

US Geological Survey (2015) M7.8 - 34 km ESE of Lamjung, Nepal. http://earthquake.usgs.gov/earthquakes/eventpage/us20002926. Accessed 29 July, 2015

Wang K, Fialko Y (2015) Slip model of the 2015 Mw 7.8 Gorkha (Nepal) earthquake from inversions of ALOS-2 and GPS data. Geophys Res Lett 42. doi:10.1002/2015GL065201 
Wessel P, Smith WH (1998) New, improved version of Generic Mapping Tools released. Eos Trans AGU 79:579

Wright TJ, Lu Z, Wicks C (2003) Source model for the Mw 6.7, 23 October 2002, Nenana Mountain Earthquake (Alaska) from InSAR. Geophys Res Lett 30(18):1974. doi:10.1029/2003GL018014

Submit your manuscript to a SpringerOpen ${ }^{\circ}$ journal and benefit from:

- Convenient online submission

- Rigorous peer review

- Immediate publication on acceptance

- Open access: articles freely available online

- High visibility within the field

- Retaining the copyright to your article

Submit your next manuscript at $\gg$ springeropen.com 